\title{
Eye movements of prereaders to pseudowords containing letters of high and low confusability'
}

\author{
CALVIN F. NODINE ${ }^{2}$ AND JAMES D. EV ANS 3
} CARNEGIE-MELLON LNIVERSITY

Children were required to make same-different judgments about matched and unmatched pseudoword pairs containing middle lettens of either high confusability (e.g.. ZPR.V) or low' confusability (e.g., EROI). Differential eye-movement patterns were observed between matched and unmatched lowconfusion pairs. This finding would be predicted from a features analysis of the visual characteristics of the letters of the pseudowords. Low-confusion pseudowords contain more different visual features than high-confusion pseudowords. Therefore, in making a matching judgment. low-confusion pairs should require more eye movements; however, detection of a mismatch should be facilitated due to the greater availability of distinctive features.

Discrimination among words for the beginning reader requires not only the ability to differentiate among letters, but also the ability to attend systematically to the letters of the word in left-to-right order (e.g.. Muehl, 1963). The present experiment was concerned with the eye-movement patterns underlying such word discriminations.

In an earlier experiment, Nodine and Hardt (in press). using the Gibson letter-confusion matrix (Gibson, Osser, Shiff, \& Smith, 1963), investigated the role of letter confusability on the discrimination of pseudoword pairs containing matched and unmatched (transposed) four-letter sequences. They found the prereaders could detect differences between "words" on between unmatched pairs). As anticipated, prereaders had more difficulty, in terms of more errors and longer decision times, with pseudoword pairs containing middle letters of high confusability (e.g.. $B M W Q$ ) than those containing middle letters of low confusability (s.g., EROI).

Of more immediate concern to the present experiment was Nodine's and Hardt's unexpected finding that decision times for matched pseudoword pairs in which the letter sequences wern identical (e.g., EROI-EROI) were slower (but more accurate) than decision times for unmatched pairs in which the middle letters of one member of the pair were transposed (e.g.,
EROI-EORI). Informal observations of Ss' eye movements as they performed the task suggested that Ss used a difierent search strategy for matched than unmatched pairs. The hypothesis was that the children used a sequential search pattern in which they searched and compared letters of the two pseudowords one at a time, alternating between words. Thus, with unmatched pairs, $\mathrm{S}$ compared the two pseudowords letter by letter until a mismatch occurred, at which point $\mathrm{S}$ terminated the search and responded "not the same." With matched pairs, however, the letter-by-letter comparisons between pseudowords continued, exhaustively, until all letters had been considered despite the fact that the critical cue was still the same second letter (this time the same letter) as with unmatched pairs.

In order to check this hypothesis, an experiment was performed similar to Nodine's and Hardt's earlier one, this time recording eye movements of the Ss as they carried out the task.

Subjects

\section{METHOD}

The Ss were seven girls (aged 5-3 to 5-7 years) and six boys (aged 5-9 to 6-3 years) who had recently completed kindergarten. One $\mathrm{S}$ was used for practice trials, and two Ss were eliminated due to $E$ errors. Data are presented on the remaining $10 \mathrm{Ss}$, five girls and five boys.

Stimuli

The stimuli were 20 four-letter pseudoword pairs. Half of the pseudoword pairs contained matched letter sequences and the other half contained unmatched letter sequences. For unmatched pairs. the order of the middle letters of the right member of the pair was transposed. In addition. each pseudoword pair was constructed so that the middle letters were of either high or low confusability as defined by th: Gibson et al letter-confusion matrix. The pseudoword pairs are shown in Table 1. A common subset of letters was used to form both high- and low-confusion (Con) pairs so that only the middle letters of the two subsets were different.

Table 1

Mean Number of Scans and Fixations, and Mean Total Fixation Time for Matched and Unmatched Preudoword Pairs of High and Low Confusability

\begin{tabular}{|c|c|c|c|c|c|c|c|c|c|c|}
\hline \multirow[b]{2}{*}{ Confusability } & \multicolumn{5}{|c|}{ Matched Pairs } & \multicolumn{5}{|c|}{ Unmatched Pairs } \\
\hline & \multicolumn{2}{|c|}{ Pseudowords } & Scans & $\begin{array}{l}\text { Fix- } \\
\text { ations }\end{array}$ & $\begin{array}{l}\text { Time } \\
(\mathrm{sec}) \\
\end{array}$ & \multicolumn{2}{|c|}{ Pseudowords } & Scans & $\begin{array}{l}\text { Fix- } \\
\text { ations }\end{array}$ & $\begin{array}{l}\text { Time } \\
(\mathrm{sec})\end{array}$ \\
\hline \multirow[t]{2}{*}{ High } & $\begin{array}{l}\text { OEFU } \\
\text { BMWQ } \\
\text { CKXI } \\
\text { SOQH } \\
\text { ZPRN }\end{array}$ & $\begin{array}{l}\text { OEFU } \\
\text { BMWQ } \\
\text { CKXI } \\
\text { SOQH } \\
\text { ZPRN }\end{array}$ & $\begin{array}{l}2.3 \\
2.8 \\
2.1 \\
2.4 \\
2.7\end{array}$ & $\begin{array}{l}6.4 \\
8.5 \\
7.3 \\
8.2 \\
9.4\end{array}$ & $\begin{array}{l}2.95 \\
4.44 \\
3.12 \\
3.68 \\
4.60\end{array}$ & $\begin{array}{l}\text { OEFU } \\
\text { BMWQ } \\
\text { CKXI } \\
\text { SOQH } \\
\text { ZPRN }\end{array}$ & $\begin{array}{l}\text { OFEU } \\
\text { BWMQ } \\
\text { CXKI } \\
\text { SQOH } \\
\text { ZRPN }\end{array}$ & $\begin{array}{l}1.8 \\
2.1 \\
1.8 \\
2.0 \\
2.2\end{array}$ & $\begin{array}{l}6.1 \\
6.6 \\
5.8 \\
6.0 \\
7.0\end{array}$ & $\begin{array}{l}3.11 \\
3.06 \\
2.64 \\
2.66 \\
3.42\end{array}$ \\
\hline & & Means & 2.46 & 7.96 & 3.76 & & Means & 1.98 & 6.30 & 2.98 \\
\hline \multirow[t]{2}{*}{ Low } & $\begin{array}{l}\text { IEMO } \\
\text { OFWS } \\
\text { UPXQ } \\
\text { AKQB } \\
\text { EROI }\end{array}$ & $\begin{array}{l}\text { IEMO } \\
\text { OFWS } \\
\text { UPXQ } \\
\text { AKQB } \\
\text { EROI }\end{array}$ & $\begin{array}{l}2.8 \\
2.7 \\
3.0 \\
2.4 \\
2.6\end{array}$ & $\begin{array}{l}8.6 \\
9.2 \\
9.1 \\
7.7 \\
8.0\end{array}$ & $\begin{array}{l}4.30 \\
4.37 \\
4.60 \\
3.29 \\
3.92\end{array}$ & $\begin{array}{l}\text { IEMO } \\
\text { OFWS } \\
\text { UPXQ } \\
\text { AKQB } \\
\text { EROI }\end{array}$ & $\begin{array}{l}\text { IMEO } \\
\text { OWFS } \\
\text { UXPQ } \\
\text { AQKB } \\
\text { EORI }\end{array}$ & $\begin{array}{l}1.5 \\
1.8 \\
1.6 \\
1.4 \\
1.6\end{array}$ & $\begin{array}{l}5.8 \\
5.7 \\
5.9 \\
4.5 \\
5.0\end{array}$ & $\begin{array}{l}2.89 \\
2.41 \\
2.56 \\
2.01 \\
2.77\end{array}$ \\
\hline & & Means & 2.70 & 8.52 & 4.10 & & Means & 1.58 & 5.38 & 2.53 \\
\hline
\end{tabular}


The pseudoword pairs were printed in l-in. caps on $16 \times 7$ in. cards. The midpoints of the letters of each pseudoword were $1.75 \mathrm{in}$. apart. The cards were placed in a slide holder $19.5 \mathrm{in}$. from S's eyes. Thus, the visual angle between letters was approximately $4 \mathrm{deg}$. A 4.5 -in. space (14.5 deg) separated the two pseudowords of a pair. The entire display was approximately $40 \mathrm{deg}$.

\section{Apparatus}

A closed-circuit television system, which included two Panasonic TV cameras and a 1-in. video tape recorder, was used to record eye movements. The S's head was held in place by a combination headrest-card rack. One TV camera with zoom lens focused on S's eyes as he looked through a Plexiglass grid graduated in 1/8 in. at the display. A second TV camera focused on a timer. Both pictures were recorded using a special-effects generator that produced a split-image picture. Sound was also recorded. The tapes were played back in slow motion in order to facilitate the measurement of eye movements.

\section{Procedure}

Each $S$ was seated in an adjustable chair so that his head rested comfortably in the headrest. Movement of the head was further restricted by placing Styrofoam wedges between each side of the head and headrest. In order to determine the position of the eyes relative to the letters on the display, Ss were required to read aloud, forward and backward, an alphabetical display arranged in the same format as the pseudoword pairs. The Ss were then read a set of instructions that described the task as an alphabet word game. Following the instructions Ss were given two practice pseudoword pairs and then 20 test pairs. Order of presentation of the pseudoword pairs was randomized for each S. Prior to the presentation of each pseudoword pair, $S$ was required to fixate on a cartoon cutout (Yogi Bear) positioned in the center of the display on a hinged shutter. The trial was initiated by $E$ raising the shutter to expose the pseudoword pair. Onset and offset of the timer was also controlled by $E$. The Ss responded by saying either "same" or "not the same" to each pair.

\section{RESULTS}

Eye movements were analyzed by $\mathrm{E}$ using slow-motion video replay. Detection of small eye movements (less than $4 \mathrm{deg}$ ) was extremely difficult using this observational technique thus precluding the measurement of eye fixations to specific letters within each pseudoword. However, large eye movements (greater than $4 \mathrm{deg}$ ) that occurred within and between pseudowords were measured.

Three measures were subjected to analysis of variance. One measure was frequency of fixations. The criterion for a fixation was a pause of the eye movement of .10 sec or longer. Duration of fixations was the second measure. A check on the reliability of these two measures was made by having $E$ rescore eye movements of two Ss selected at random. A test-retest reliability of $r=.93$ was obtained for the frequency measure, and $r=.95$ was obtained for the duration measure. The average duration of fixation was $.47 \mathrm{sec}$, which fits expectations based on Taylor's (1957) data. He reported that average duration of fixations systematically decreased from a maximum of $.33 \mathrm{sec}$ for first-grade children to $.27 \mathrm{sec}$ for fourth-grade children. The third measure was frequency of scans. A scan is a derived measure that combines in one score the total number of progressive (left-to-right) and regressive (right-to-left) fixations contained in a sweep of the entire visual display. Scans give a gross indication of the number of comparisons between left and right members of the pseudoword pair. In 190 out of 200 cases the first scan was initiated on the left side of the display.
Letter confusability (Con), as a main effect, failed to produce differences for all three eye-movement measures. However, Con interacted with pairings for scans, fixations, and fixation time. Table 1 shows mean number of scans and fixations and mean fixation times (left and right words combined) for matched and unmatched pairs of high and low Con.

\section{Scans}

More scans occurred with matched (2.58) than unmatched (1.78) pairs, $F(1,49)=41.75, p<.001$. Con interacted with pairings. $F(1,49)=33.36, p<.001$. This interaction was due to more scans for low-Con than high-Con pseudowords with matched pairs; however, with unmatched pairs the reverse was true. Both differences were significant $(q=.24, p=.01$ by Tukey, HSD).

\section{Fixations}

A similar response pattern was present for fixations. More fixations occurred with matched (8.24) than unmatched (5.84) pairs, $F(1,49)=49.46, p<.001$. Con again interacted with pairings, $F(1,49)=4.29, p<.05$. This interaction was due to the fact that significantly more fixations occurred for matched than unmatched low-Con pairs $(q=2.18, p=.01)$. A similar but less pronounced pattern was present for high-Con pairs. The difference between matched and unmatched pairs in this case was nonsignificant. More fixations occurred to the left $(7.66)$ word than the right $(6.42)$ word, $F(1,49)=14.03$, $\mathrm{p}<.001$.

\section{Fixation Time}

More fixation time was required for matched (3.94 sec) than unmatched $(2.76 \mathrm{sec})$ pairs, $F(1,49)=40.00, p<.001$. Con interacted with pairings, $F(1,49)=8.66, p<.01$. More fixation time was required for matched than unmatched low-Con pairs $(\mathrm{q}=.82, \mathrm{p}<.01)$. The difference between matched and unmatched high-Con pairs was in the same direction, but smaller and nonsignificant. Finally, more fixation time was spent on the left $(3.70 \mathrm{sec})$ word than on the right $(2.98 \mathrm{sec})$ word, $F(1,49)=14.01, \mathrm{p}<.001$.

\section{DISCUSSION}

A consistent pattern was revealed by three eye-movement measures: scan rate, fixation rate, and fixation times. More and longer eye movements were associated with matched than unmatched pairs. Moreover, letter confusability interacted with pairings for all three measures. These interactions resulted primarily from differential eye-movement patterns between matched and unmatched low-Con pseudowords. This differential pattern was less pronounced between matched and unmatched high-Con pseudowords.

The results are consistent with the hypothesis that prereading Ss search and compare pseudowords letter by letter alternating between members of the pair. When Ss detect a mismatch between letters of the two words, they terminate their search. If no mismatch is detected, the search continues exhaustively. This description accounts for effects of the pairings variable, and agrees with findings obtained on pattern-matching tasks by adult Ss (e.g., Gould \& Schaffer, 1967).

The fact that pairings interacted with confusability adds another dimension to the analysis. Assuming as have others (e.g., Gibson et al, 1963; Laughery, 1967) that lowconfusability pseudowords contain more different visual features than high-confusability pseudowords. it follows that with matched pairs low-Con pseudowords should require more and longer fixations than high-Con pseudowords due to the fact that $S$ has more features to consider in making a matching judgment. However, detection of a mismatch should be 
Table 2

Number of Different Visual Features between High and Low Confusability Pseudowords

\begin{tabular}{lccc}
$\begin{array}{l}\text { High } \\
\begin{array}{l}\text { Confusability } \\
\text { (Middle Letters) }\end{array}\end{array}$ & $\begin{array}{l}\text { Number of } \\
\text { Different } \\
\text { Features }\end{array}$ & $\begin{array}{l}\text { Low } \\
\text { Confusability } \\
\text { (Middle Letters) }\end{array}$ & $\begin{array}{l}\text { Number of } \\
\text { Different } \\
\text { Features }\end{array}$ \\
\hline EF & $1^{I}$ & FW & 7 \\
KX & 2 & RO & 4 \\
MW & 0 & KQ & 3 \\
OQ & 1 & PX & 5 \\
PR & 1 & EM & 8 \\
\hline
\end{tabular}

1 Based on Laughery's (1967) scheme.

facilitated by the large number of different features in low-Con words relative to high-Con words. Thus. fewer fixations and time should be required to find a distinctive feature in unmatched low-Con pairs that leads to a "different". judgment. Table 2 shows the number of different visual features between high and low-Con pseudowords (middle letters only) using Laughery's (1967) scheme.

Our interpretation of the eye movements of prereaders stresses the importance of visual cues in making discriminations between letter sequences. At this stage of learning to read, children are highly dependent on visual features of the stimuli for information. The role of memory is minimized despite the fact that they have a system for naming the letters of the alphabet.

The analysis of eye movements has provided a tentative description of the search process used by beginning readers in making discriminations among words. The conclusions are tentative because only large eye movements were analyzed Research in progress will help clarify the role of the search process in word discriminations and its relation to the acquisition of reading skill.

\section{REFERENCES}

GIBSON, E., OSSER, H., SHIFF, W., \& SMITH, J. An analysis of crit :al features of letters tested by a confusions matrix. Cooperative Reswarch Project No. 639, Cornell University, 1963.

GOULD. J. D., \& SCHAFFER, A. Eye-movement parameters in pattern perception. Journal of Experimental Psychology, 1967, 74. 225-229.

LAUGHERY, K. R. Computer simulation of memory processes. Progress Report, MH 11595, SUNY at Buffalo, 1967

MUEHL, S. Relation between word-recognition ertors and hand-eyo preference in preschool children. Journal of Educational Psychology, $1963,54,316-321$

NODINE, C. F., \& HARDT, J. V. Effects of letter confusability on the discrimination of pseudowords by prereaders. Journal of Fducational Psychology, in press.

TAYLOR, E. A. The spans: Perception, apprehension, and recoenition A merican Journal of Ophthalmology, 1957, 44, $501-507$

\section{NOTES}

1. This research was supported by Research Grant MH 07722 from National Institutes of Health. This paper was presented at the Psychonomic Society meeting in St. Louis, Missouri, 1968.

2. Address: Department of Psychology, Carnegie-Mellon University, Pittsburgh, Pennsylvania 15213.

3. This research was carried out while the second author was an NSF undergraduate research fellow, URP program GY-4635. Now at lowa State University.

(Accepted for publication December 23, 1968.) 